\title{
Questionnaire as an Additional Method for Studying the Prevalence of Infections with a Predominantly Sexual Mode of Transmission
}

\author{
Shevnina E, Lysogorskaya I, Tkachenko T, Karpov D, Fedchenko P, \\ Osipova A and Fishman B* \\ Institute of Medical Education, Yaroslav-The-Wise Novgorod State University Ministry of \\ Education and Science of the Russian Federation, Russia
}

\section{Research Article \\ Volume 2 Issue 9}

Received Date: August 18, 2018

Published Date: August 28, 2018

*Corresponding author: Boris Fishman, Institute of Medical Education, Yaroslav-The-Wise Novgorod State University Ministry of Education and Science of the Russian Federation, Russia, Email: Fishman@mxc.ru

\section{Abstract}

The analysis of the data obtained from the state statistical supervision forms during 2008 has shown the tendency of a decrease in the majority of sexually transmitted infections (STI). However, an unfavorable situation still remains in a number of territories of the Russian Federation, especially in the Siberian, the Far East, the Privolzhsky, the Urals and the North West Federal Districts. The social importance of the STI problem is demonstrated by a high level of mor-bidity in children and the growth in their house contamination. On a back-ground of a decrease in the majority of infections, the indicators of morbidity caused by virus infections keep the tendency to grow. The prevalence of infections with a predominantly sexual mode of transmission in one of the urban areas of St. Petersburg according to various sources was studied: questionnaires, requests for medical assistance, and the results of medical examinations. To confirm the diagnosis, it is necessary to use clinical-bacterioscopic methods. The trends of both decrease and growth of individual infections are noted. It is emphasized that to obtain more accurate data on the prevalence of sexually transmitted infections, it is necessary to use various sources of information.

Keywords: Prevalence of Sexually Transmitted Infections; Medical Checkup; Bacterioscopy

\section{Introduction}

Predominantly sexually transmitted infections (PSTI) and accompanying diseases of the urogenital tract occupy a significant place among infectious pathologies. PSTI incidence is high and continues to increase from year to year. According to WHO, sexually transmitted infections are the most common in the world and are the cause of acute diseases, infertility, persistent disability and mortality, have serious medical and psychological consequences for millions of men, women and children. The impact of these diseases is exacerbated by the fact that they can contribute to the spread of HIV, which is significant in the current epidemiological situation of this infection [1-5]. 


\section{Virology \& Immunology Journal}

For more detailed characteristics of individuals suffering from this pathology, various methods are used. One of the promising areas for studying the prevalence of PSTI is the questionnaire method, which allows obtaining additional characteristics of those who applied to medical organizations. The results of the questionnaire supplement information on the incidence of PSTI for treatment in medical organizations and data of medical examinations. Analysis of the effectiveness of medical examinations (preventive, periodic and other) for the purpose of early detection of PSTI is necessary, since medical examinations are one of the important links in the epidemiological control of their spread. To diagnose a PSTI, of all methods, bacterioscopy is obligatory.

\section{Methods}

Persons who applied for medical help in the 8 dermatovenerologic dispensary of Saint-Petersburg, Russian Federation filled out the questionnaire at the time of admission. Questions included were related to the medical and social characteristics of the applicants, their lifestyle, social status, sexual behavior, the level of awareness of sexually transmitted diseases, marital status, sexual activity. For a more detailed study of the organization of medical care and its evaluation, patients were divided into groups by age and sex. These questionnaires were supplemented by the results of laboratory studies.

The sample set was formed with the help of multistage, nested, conjugate and targeted selection by random sampling from the total number of applicants and includes 215 questionnaires.

An epidemiological study was conducted among the patients of the department for prophylactic medical examinations in dermatovenerologic dispensary subject to periodic preventive medical examinations. The prevalence of syphilis, gonorrhea, trichomoniasis and other presominantly sexually transmitted infections has been determined. Among the surveyed contingent, risk factors for the development of PSTI were identified, and groups of examinees were identified that required special attention during treatment. The features of sexual behavior have been studied, and their tendency to risk sexual behavior has been established.

Patient's appeals for medical treatment to dermatovenerologic dispensary and to other local medical institutions were collated. Calculations of intensive and extensive incidence rates were carried out.

\section{Results}

The reason for the treatment of men in $62.5 \%$ was casual sexual intercourse; $32.1 \%$ had a regular sexual partner; $37.5 \%$ applied after a casual sexual intercourse of a regular sexual partner; $35.4 \%$ were sent by specialists from other medical institutions; $47.1 \%$ of men applied for preventive examination, of them $6.9 \%$ before planning pregnancy with a sexual partner, including in vitro fertilisation (IVF).

\begin{tabular}{|c|c|c|c|c|c|}
\hline \multirow[t]{2}{*}{ Gender } & \multicolumn{2}{|c|}{ Men } & \multicolumn{2}{|c|}{ Women } & \multirow{2}{*}{\begin{tabular}{|c} 
Total \\
215
\end{tabular}} \\
\hline & 102 & 47.4 & 113 & 52.6 & \\
\hline \multicolumn{6}{|c|}{ Age } \\
\hline $20-29$ & 37 & 46.8 & 42 & 53.2 & 79 \\
\hline $30-39$ & 36 & 48.6 & 38 & 51.4 & 74 \\
\hline 40 and older & 29 & 46.8 & 33 & 53.2 & 62 \\
\hline \multicolumn{6}{|c|}{ Education } \\
\hline $\begin{array}{c}\text { Higher or incomplete } \\
\text { higher }\end{array}$ & 17 & 31.5 & 37 & 68.5 & 54 \\
\hline Vocational & 83 & 59.7 & 56 & 40.3 & 139 \\
\hline Initial or no education & 10 & 45.5 & 12 & 54.5 & 22 \\
\hline \multicolumn{6}{|c|}{ Civil status } \\
\hline Married & 35 & 42.2 & 48 & 57.8 & 83 \\
\hline Not married & 67 & 50.8 & 65 & 49.2 & 132 \\
\hline \multicolumn{6}{|c|}{ Reason for application } \\
\hline Complaints & 18 & 32.1 & 38 & 67.9 & 56 \\
\hline $\begin{array}{l}\text { Casual sexual } \\
\text { intercourse }\end{array}$ & 35 & 62.5 & 21 & 37.5 & 56 \\
\hline $\begin{array}{c}\text { Direction of another } \\
\text { specialist }\end{array}$ & 17 & 35.4 & 31 & 64.6 & 48 \\
\hline $\begin{array}{c}\text { Casual sexual } \\
\text { intercourse by partner }\end{array}$ & 9 & 37.5 & 15 & 62.5 & 24 \\
\hline Pregnancy & 7 & 58.3 & 5 & 41.7 & 12 \\
\hline Preventive examination & 16 & 47.1 & 18 & 52.9 & 34 \\
\hline Diagnosed PSTI & 69 & 46,6 & 79 & 53,4 & 148 \\
\hline
\end{tabular}

Table 1: Characteristics of the interviewed persons according to certain social features.

Among the men surveyed, persons with an average vocational education prevailed $-59.7 \%$; $31.5 \%$ had a higher or incomplete higher education, $8.8 \%$ of respondents had no education or an initial (Table 1).

The social composition of the respondents was represented by persons without definite employment $33.4 \%$. At the same time, $66.5 \%$ of respondents are socially adapted citizens (working and students), what is comparable with the data presented in the works $[4,6,7]$. 
There were 69 cases of PSTI among surveyed men, which is $67.6 \%$ of the incidence of PSTI, of them $23.2 \%$ of the incidence among those who addressed with a preventive goal.

In the age category of 20-29 years, the highest prevalence of genital herpes is observed - 36.4\%, urogenital ureaplasmosis prevalence is $22.7 \%$, what is comparable with the data presented in the works [4].

In $75 \%$ of cases of genital herpes and $60 \%$ of cases of all PSTI are people with vocational or incomplete vocational education.

\begin{tabular}{|c|c|c|c|}
\hline Age & Diagnosis & Number & $\mathbf{\%}$ \\
\hline \multirow{2}{*}{$20-29$} & Genital herpes & 8 & 36.4 \\
\cline { 2 - 4 } & Ureaplasmosis & 5 & 22.7 \\
\hline \multirow{2}{*}{$30-39$} & Chlamidiosis & 12 & 41.4 \\
\cline { 2 - 4 } & Papillomavirus infection & 9 & 31 \\
\hline \multirow{2}{*}{40 и старше } & Trichomoniasis & 9 & 50 \\
\cline { 2 - 4 } & Genital herpes & 3 & 16.7 \\
\hline
\end{tabular}

Table 2: Age characteristics of SPTI male patients.

In 30-39 years age category, the greatest number of detected pathology are urogenital chlamydiosis - $41.4 \%$ and papillomavirus infection - 31.0\% (Table 2). In 58.3\% of urogenital chlamydia was detected in people with vocational or in-complete vocational education and $66.7 \%$ of the papillomavirus infection are people with higher education what is comparable with the data presented in the works [8-11].

In the age category of 40 years and older, predominant diagnoses were trichomoniasis - 50\% and genital herpes$16.7 \%$ of cases. In $62.5 \%$ of cases of trichomoniasis patients were people with vocational or incomplete vocational education, with the data presented in the works [4]. 50.8\% of patients with PSTI were not married, which can be considered as a factor that promotes the spread of casual sex and the spread of sexually transmitted diseases.

The reason for application of women in $37.5 \%$ was casual sexual inter-course; $67.9 \%$ had regular sexual partner; $64.6 \%$ were sent by specialists from other medical institutions; $52.9 \%$ of women applied for preventive examination, $14.4 \%$ of them before planning for pregnancy and during pregnancy.

Among the women surveyed, persons with higher and incomplete higher education prevailed - 39.8\%; $49.6 \%$

\section{Virology \& Immunology Journal}

had vocational education, $10.6 \%$ had no or initial education. Among PDTI diagnosed respondents, 31\% were without certain employ-ment. At the same time, $69.0 \%$ of respondents are socially adapted citizens (working and students).

79 cases of registration of PSTI among women of all age groups directed for inspection have been revealed, which is $70 \%$ of the incidence of PSTI, including $22.8 \%$ of the incidence among those who addressed with a preventive goal.

\begin{tabular}{|c|c|c|c|}
\hline Age & Diagnosis & Number & \% \\
\hline \multirow{2}{*}{$20-29$} & Ureaplasmosis & 15 & 41.7 \\
\cline { 2 - 4 } & Papillomavirus infection & 8 & 22.2 \\
\hline \multirow{2}{*}{$30-39$} & Trichomoniasis & 14 & 50 \\
\cline { 2 - 4 } & Genital herpes & 7 & 25 \\
\hline \multirow{2}{*}{40 and older } & Ureaplasmosis & 7 & 46.7 \\
\cline { 2 - 4 } & Chlamidiosis & 4 & 26.7 \\
\hline
\end{tabular}

Table 3: Age characteristics of SPTI female patients.

In 30 - 39 years age category, the prevailing pathology among diagnoses is urogenital ureaplasmosis- $41.7 \%$, papillomavirus infection-22.2\% (this is confirmed by a number of authors). $55 \%$ of diagnosed cases of urogenital ureaplasmosis were people with vocational or incomplete vocational education, $69.2 \%$ of papillomavirus infection were people with higher education.

In age category of 30-39 years, the greatest number of detected pathology is trichomoniasis - 50\%, genital herpes-25\% (Table 3). $61.1 \%$ of cases of trichomoniasis are in patients with vocational or incomplete vocational education, $55.6 \%$ of cases of genital herpes are in individuals with higher education. In the age category of 40 years and older, $46.7 \%$ of cases of diagnosis is urogenital ureaplasmosis, $26.7 \%$ - is genital chlamydiosis.

Persons with vocational or incomplete vocational education have been diagnosed with urogenital ureaplasmosis in $58.3 \%$ of PSTI diagnoses and contribute $57.1 \%$ of all diagnosed PSTI. In the group of socially adapted patients, diagnosed PSTI are more prevalent among workers $(34.0 \%$ for men and $34.8 \%$ for women respectively), second place among patients with PSTIstudents of all types of educational institutions (12.8\%).

Not married individuals accounted for $43.3 \%$ of the male and $56.7 \%$ female patients with PSTI, which can be seen as a factor contributing to the spread of casual sex and PSTI (Table 4). 
Noteworthy is the fact that of $48.7 \%$ patients are ignorant of circumstances, under what the infection occurred. Of those who indicated the circumstances and source of infection, $23.6 \%$ of patients with PSTI and $27.7 \%$ noted a casual sexual partner. Frequent change of sexual partners was noted in $35.8 \%$ of cases among patients with PSTI. Men changed their sexual partners more often compared to women during the year.

\begin{tabular}{|c|c|c|c|c|c|}
\hline & Men (\%) & \multicolumn{2}{c|}{ Women (\%) } & Total \\
\hline Total respondents & 102 & 47.4 & 113 & 52.6 & 215 \\
\hline $\begin{array}{c}\text { Respondents } \\
\text { diagnosed with SPTI }\end{array}$ & 69 & 46.6 & 79 & 53.4 & 148 \\
\hline \multicolumn{7}{|c|}{ Age } \\
\hline $20-29$ & 22 & 37.9 & 36 & 62.1 & 58 \\
\hline $30-39$ & 29 & 50.9 & 28 & 49.1 & 57 \\
\hline 40 and older & 18 & 54.5 & 15 & 45.5 & 33 \\
\hline \multicolumn{7}{|c|}{ Civil state } \\
\hline Married & 27 & 52.9 & 24 & 47.1 & 51 \\
\hline Not married & 42 & 43.3 & 55 & 56.7 & 97 \\
\hline
\end{tabular}

Table 1: Age and civil state of respondents.

At least one third among patients with PSTI obey no rules to avoid exposing partners to the risk of contamination. In addition, $57.4 \%$ of patients very rarely use barrier contraceptives as a means of preventing PSTI.

A significant proportion (29.0\%) of patients with PSTI sought medical assistance after one month or more after the appearance of the first symptoms. The main reasons are low level of knowledge about PSTI and a fear of breach of medical secrecy. This fact indicates the need for greater alertness and raising the level of knowledge of medical professionals in the general treatment network about the first symptoms and differential diagnosis of PSTI.

The survey indicated a low level of knowledge about PSTI: $46.8 \%$ do not suspect that they are at risk of exposing to PSTI such as gonorrhea, trichomoniasis and chlamydiosis in unprotected sex, and one in five $(21,9 \%)$ does not know at all, than one can get infected during a non-protected sexual contacts.

Patients diagnosed with PSTI have the following risk factors: antisocial lifestyle, promiscuous sexual intercourse that leads to the spread of infections with a predominantly sexual mode of transmission. Consequently, the prevention of classical STI and PSTI should be based on the same principles and should be directed not only to people of active sexuality, but also to

\section{Virology \& Immunology Journal}

students of various educational institutions, including school children.

The results of periodic medical examinations with the collection of an amnestic data showed that syphilis is more often registered with age categories from 15-19 years old, and in the 20-29 year category - often in unmarried or having an adultery sex relationship women, married, with unprotected sex. The increase of cases of syphilis in age categories of 30-39 years and 40 and older has been noted. It was noted that prevailing number of PSTI patients were not married (single or divorced). In all cases, syphilis was diagnosed as initial find, this is confirmed by a number of authors $[4,7,12-14]$.

In the general structure of diagnosed diseases of the urogenital tract, candidal colpitis (about 30 per 1000 examined) was found on the first place, bacterial vaginosis (about 19 per 1000 people examined) at the second place and trichomoniasis at the third (about 8.6 per 1000 examined).

According to the results of periodic surveys with the collection of an amnestic data, there is a noticeable tendency to decrease of early incidence of trichomoniasis. This pathology is most often registered in the age category of 40 and more years, more often in women who have casual sexual intercourse, single and divorced. In the epidemic process, slow progressive forms of the disease, as well as asymptomatic carrier-type infection, were important. In such conditions, there are not many stimuli to apply for medical help but there is a high percentage of detectability of this pathology precisely with preventive medical examinations. In this case, signs of inflammation are absent, and the causative agent is to detect in relapses of inflammatory process in both infected partners. Asymptomatic trichomoniasis is not a simple transitional carrier-type infection, but an active infectious process with systemic reaction to the pathogenic factor. Asymptomatic trichomoniasis contributes greatly to the epidemiological spread of the pathogen among sexual partners.

During preventive medical examination, skin pathologies were diagnosed, including epidemic significant ones (hands and feet onychomycosis, common warts, epidermophytosis). This, of course, contributed to the infection of other members of population and the spread of infection.

The study of appliance showed that the incidence of PSTI for 100 thousand people was 363.4, including syphilis - 51.5, gonorrhea - 20.6, PSTI (trichomoniasis, 


\section{Virology \& Immunology Journal}

chlamydia, urogenital herpes, genital warts) - 291, 3. Asymptomatic and late forms were 52\%, including late neurosyphilis-1.5\%. Among the PSTI patients, the percentage of men and women was 61:39 with syphilis, 80: 20 with gonorrhea, 48: 59 with chlamydia, 31: 69 with trichomoniasis, 38:62 with urogenital herpes and genital warts. Women more frequently undergo examination with complaints about various inflammatory processes in the genitourinary area and for the purpose of examination for PSTI, which can be considered as an indicator of the active work of obstetricians and gynecologists.

The social aspect is also indicative: among patients with syphilis and gonorrhea-about half were unemployed (52\%). Significantly higher PSTI incidence is observed among the contingent of 20-29 years, which is explained by the high attendance to dermatovenerologic dispensary in this age. A high number of young women are applying for a preventive PSTI examination, planning the birth of healthy offspring [15-29].

In the age group 15-19 years, the most common among PSTI in descending order, were the following: ureaplasmosis, chlamydiasis, genital warts, and among infections not directly related to the PSTI group candidiasis and gardnerellosis, and the best examination coverage and PSTI detection rates are noted by gynecologists of women's consultations. PSTI pathogens in adolescent girls are often combined with bacterial vaginosis, candidiasis and increased concentration of opportunistic microflora (more than 104 CFU(colonyforming unit) $/ \mathrm{ml}$ ); in the age category of 20-29 years, the most common among PSTI in descending order, were the following: ureaplasmosis, HPV (genital warts), chlamydiasis, and among infections not directly related to PSTI - candidiasis and gardnerellosis; in the age category 30-39 years, ureaplasmosis takes the first place, then are viral infections (genital warts, genital herpes). Mostly stable, by a venereologists, gynecologists and urologists data, are condylomas, genital herpes incidence rates, other diseases can have a wavy course.

\section{Summary}

1. The optimal mechanism for reducing the incidence of PSTI is the medical and social program of interdepartmental prevention aimed at enhancing the activities of state and municipal government to improve the three main inte-grated areas that determine human health (environment, organism, behavior) with information support aimed at forming a youth commitment to a healthy lifestyle while satisfying their needs freedoms.

2. The need for periodic medical examinations is very high, assuming constant registration of new cases of syphilis, PSTI, detection of asymptomatic, lowsymptom forms of PSTI and skin pathology, which have epidemiological significance. Obligatory examination of sexual contacts, treatment of PSTI and syphilis patients and follow-up treatment leads to a sharp decrease in incidence of PSTI patients due to periodic examinations. As a result of periodic examinations and treatment there was a significant decrease in the number of patients with syphilis and PSTI, which significantly reduced the risk of population spread of infection. Detectability of asymptomatic, low-symptom forms of trichomoniasis in preventive medical examinations is of great importance, as appeal to dermatovenerologic dispensary with those is extremely low.

3. The presented data indicate the need of interaction between dermatovenereological service, obstetriciangynecologists, urologists for increasing detection of PSTI, examination of sexual contacts, identification of the source of infection, conducting control methods after treatment, and dynamic follow-up. The results obtained provide materials for the development of PSTI prevention programs.

\section{References}

1. Afonin AV, Riumin DV (2004) STIs problems in some developed countries: the epidemiological situation, changes in social behavior as a distribution factor, methods of prevention. Bulletin posledipl pp: 59-64

2. Krasnopolskiy VI (1997) Pathology of the vagina and cervix uteri. Medicine pp: 83.

3. Kubanova AA, Lesnaya IN, Kubanov AA (2010) The analysis of the epidemiological sit-uation and the dynamics of infection diseases, sexually transmitted infections, dermatoses and in the Russian Federation. Journal of Dermatology and Venereology 5: 4-21.

4. Schaller U, Klauss V (2001) Is Credé's prophylaxis for ophthalmia neonatorum still valid? Bull World Health Organ 79(3): 262-263.

5. Jakopanec I, Grjibovski AM, Nilsen O, Aavitsland P (2010) Syphilis epidemiology in Norway, 1992-2008: resurgence among men who have sex with men 10 : 105. 


\section{Virology \& Immunology Journal}

6. Kirgueva M (2008) Epidemicheskii nadzor za IPPP/VICH: obzor po stadiiam Clinich dermatolo-gii I venerologii 4: 30-34.

7. Porkes R, Renton A, Meheus A (2004) Review of current evidence and comparison of guidelines for effective syphilis treatment in Europe. Int J STD AIDS 15: 73-88.

8. European Centre for Disease Prevention and Control (2011) Sexually transmitted infections in Europe 1990-2009.

9. Sergeeva I (2010) Analiz pokazatelei reproduktivnogo I somaticheskogo zdorovia $u$ genshin s IPPP. Vestnic dermatologii I venerologii 6: 124-129.

10. Chamaganovai I (2009) Raspsprostranennost smechannoi chlamidiino-mikoplazmennoi infekcii $\mathrm{v}$ usloviiach megapolisa. Venericheskich zabolevanii 2: 57-58.

11. Bag S, Deep N, Dasmahapatra S (2011) Women and HIV/AIDS. J Indian Med Assoc 109(1): 42-43.

12. Doherty L, Fenton Hanquet G, IPH ID team (2003) News on outbreak and infectious diseases.

13. Van de Laar MJ, van Veen M, Gotz H, Nuradini B, van der Meijden W, et al. (2003) Ontinued transmission of syphilis in Rotter-dam, the Netherlands. Eurosurveillance Weekly 7.

14. Petzoldt D, Jappe U, Hartmann M, Hamouda O (2002) Sexually transmitted diseases in Germany. Int J STD AIDS 13(4): 246-253.

15. Roth A, Van Der Pol B, Dodge B, Fortenberry JD, Zimet G (2011) Future chlamydia screening preferences of men attending a sexually transmissible infection clinic. Sex Health 8(3): 419-426.

16. Terris-Prestholt F, Watson-Jones D, Mugeye $\mathrm{K}$, Kumaranayake L, NdekIs L, et al. (2003) Is antenatal syphilis screening still cost effective in sub-Saharan Africa? Sexually Transmitted Infections 79(5): 375381.

17. Zuppa AA, D'Andrea V, Catenazzi P, Scorrano A, Romagnoli (2011) Ophthalmia neonatorum: what kind of prophylaxis? J Matern Fetal Neonatal Med 24(6): 769-773.
18. Salomón MC, Martínez N, Delgado D, González Arra C, Bittar V (2011) Trichomonas vaginalis prevalence in sex workers. Medicina (B Aires) 71(5): 429-431.

19. Zetola NM, Engelman J, Jensen TP, Klausner JD (2007) Syphilis in the United States: an up-date for clinicians with an emphasis on HIV coinfection. Mayo Clin Proc 82(9): 1091-1102.

20. Centers for Disease Control and Prevention. Sexually Transmitted Disease Surveillance (2006) Atlanta, GA: U.S. Department of Health and Human Services, Centers for Disease Control and Prevention, November 2007.

21. Su JR, Beltrami JF, Zaidi AA, Weinstock HS (2011) Primary and secondary syphilis among black and Hispanic men who have sex with men: case report data from 27 States. Ann Intern Med 155(3): 145-151.

22. Fenton KA, Lowndes CM (2004) The European Surveilance of Sexually Transmitted Infections (ESSTI) Network. Recent trends in the epidemiology of sexually transmitted infections in the European Union. Sex Transm Infect 80: 255-263.

23. Panchaud C, Singh S, Feivelson D, Darroch JE (2000) Sexually transmitted diseases among adolescents in developed countries. Fam Plann Perspecr 32(1): 2432.

24. Axelsen N, Smith E, Koch-Ilansen GH (2002) Syphilis cases increasing in Denmark, 2000-01. Eurosurveillance Weekly 6.

25. Hiltunen-Back E, Haikala O, Koskela P, Vaalasti A, Reunala T (2002) Epidemics due to imported syphilis in Finland. Sex Transm Dis 29(12): 746-751.

26. European health for all database (HFA-DB) World Health Organization Regional Office.

27. Majewski S, Rudnicka I (2013) Sexually transmitted diseases in Poland in 2011. Przegl Epidemiol 67(2): 283-286.

28. Sexually transmitted infections: update (2013) Praxis (Bern 1994) 102(5): 273-278.

29. Potekaev N, Frigo N, Almasova A, Le-bedeva G (2015) Epidemiologia sifilisa $\mathrm{v}$ sovremennich usloviiach. Klinicheskaia dermatologia I venerologia 14(1): 2234. 